\title{
Research on Performance Auditing Standards System Construction of Energy-saving Emission and Reduction Projects
}

\author{
Tian Jinyu \\ School of North China Electric Power University \\ Baoding, China \\ 434668545@qq.com
}

\author{
He Sijia \\ School of North China Electric Power University \\ Baoding, China \\ 604526880@qq.com
}

\begin{abstract}
This paper takes system construction as a starting point and performance auditing of energy saving and emission reduction as the key point. By gathering relevant evaluation criteria and parameters of energy saving and emission reduction, redundant and duplicate parts are removed to construct a performance auditing standard system for energy saving and emission reduction according to the relationships between standards. With a complete and applicable standard system, performance implementation of energy saving and emission reduction can be well measured and evaluated, which will provide a better foundation for implementation of energy saving and emission reduction.
\end{abstract}

Keywords - performance auditing; energy saving and emission reduction; standard system

\section{NECESSITY OF STANDARD SYSTEM CONSTRUCTION FOR ENERGY SAVING AND EMISSION REDUCTION}

With the rapid development of economy and the increase in energy consumption, environmental pollution is becoming more and more serious. Countries around the world are no longer ignore it when they face unprecedented serious energy and environmental problems. The requirement to carry out the energy conservation and emissions reduction becomes urgent. How to reconcile the economic development and environmental protection has become the focus of people from all walks of life to explore. The theory of circular economy is the research achievement of the relation between economy and environment. It is the economic development mode that economic development is not at the expense of the environment pollution. It requires enterprise to comply with the principle of sustainable development. In the process of the development of today's enterprise, industries especially those who would be very damaging to the environment should persist to the concept of circular economy to achieve economic development goals. China's energy-saving emission reduction performance audit is facing many problems, the most prominent is the audit information sharing, the implementation of the audit results to the blank and standard system. In a long time, nature of audit supervision and enforcement departments is in the lack of necessary coordination, the supervision of audit information flow in the text, the line is not a strength, and the audit results announcement difficult problem rectification. Energy saving and emission reduction performance audit is the basic situation of the audit items through the understanding, to determine the scope of the audit, understand the relevant pollution control projects in the background, progress and problems in implementation, environmental monitoring and statistical data, analysis of pollutant emissions data, the main concern ring water economic zone and pollutant sources of pollution, and then make the key content, audit objectives, audit implementation audit, submit audit reports to the audit information in a timely manner. Sharing the audit results timely notice is the implementation of energy-saving emission reduction management responsibility in the process of defects and providing suggestions to the relevant departments, ongoing supervision and to improve the problem. In addition, the dislocation of statistical supervision and enforcement of the audit information sharing is another important reason for difficulties of the criteria and indicators of understanding and application of the lack of unified understanding.

Our country pays more and more attention to energy conservation and emissions reduction work. The theory researchers of auditing and the practitioners of auditing begin to research the energy conservation and emissions reduction environmental auditing. They have researched the environmental audit procedures, mode and evaluation index of energy conservation and emissions reduction environment auditing and obtain certain research achievement. But the research on the energy conservation and emissions reduction environmental performance auditing evaluation index is not perfect enough. It has not have an scientific, feasibility and high maneuverability's evaluation index system. The theory researchers of auditing and the practitioners of auditing still need to continue to strengthen the research and to make up the shortfall. When we research the energy conservation and emissions reduction environmental performance auditing, it is the inevitable requirement of economic development to refer to the circular economy .It is also decided by the correlation and the internal consistency between circular economy and energy conservation and emissions reduction environmental performance auditing. If we can evaluate the enterprise's environmental performance under circular economy, then we can let the comprehensive supervision, verification and evaluation of energy saving and emission reduction environmental performance come true. 


\section{PRINCIPLES OF STANDARD SYSTEM CONSTRUCTION FOR ENERGY SAVING AND EMISSION REDUCTION}

\section{A. Systematic principles}

The establishment of the principle of system is the system should pay attention to the relevance and typical selection criteria, according to the relationship between the standard constructions of a complete system. The construction of any system cannot ignore the principle of the system, the system requirements in the standard selection process, pay attention to the relationship between the standard, single index there must be enough delegates and summary, starting from the whole system, measure the applicability of the selection criteria, guarantee the sufficient typical system at the same time, to ensure the practical standard system, which can reflect the society, economy, interaction between the environment of the three are mutual influence and promote each other, and can the three change with its own development leads to changing the relationship between the three.

\section{B. Clarity principle}

Principle of clarity requirements selection criteria, which the standard system must be simple and clear, can reflect the energy saving and emission reduction related matters clearly the actual progress. The audit results in the target population to understand the weakness, which weaken the performance audit of its own effect. Therefore, the construction of the standard system can not be able to respond in full to the actual situation. The construction of the standard system should pay attention to the standard system of concise clearly, which make performance audit process transparent and understandable, not create obstacles to the understanding of the target population.

\section{Dynamic principle}

The dynamic principle for constructing a flexible system should avoid using mechanical and rigid standard. Because the social, economic, natural environment is a dynamic interaction, and with the development of energy saving and emission reduction performance audit theory and event, the performance auditing standard system of energy saving and emission reduction must be a dynamic system. It can not only describe the real situation of energy saving and emission reduction in a certain historical period, but also in a relatively stable period of the appropriate measure and evaluate the development trend of energy saving and emission reduction, and can adjust its system structure according to the various factors of future changes, which can still play a crucial effect of energy saving and emission reduction in the performance audit process.

\section{Regional principle}

The principle of regional requires for the establishment of the system of the regional factors into consideration. Especially, the unbalanced development of science and technology, economy, geography, hydrology conditions are different in our country. So the energy saving and emission reduction performance standard system construction must take into account regional factors in our country. Different kinds of social environment and the natural environment should be taken into the system of consideration according to local conditions, which will make it become a perfect system rather than a special system of industry in a certain area.

\section{E. Applicability Principle}

The applicability principle refers to the establishment of a standard system for the process to considering the audited object available for audit operation. Appropriate selection principle on the standard requires concise, simple and clear, easy to understand, which can be clearly reflected. The target indicators have measurable indicators, and the content is scientific and measurable. Standard should also be comparable to the same industry with the enterprise's own history and current, future than in different regions or in different countries. In addition, the selection index of related factors should be identified as controllable and uncontrollable. The formation of the index is not reliable, so the ultimate goal of energy saving and emission reduction performance audit is to control the excessive consumption of resources and damage to the environment, uncontrollable factors will weaken the system of energy saving and emission reduction performance audit. The standard system is applicable to the test of its time.

\section{CONTENTS OF STANDARD SYSTEM CONSTRUCTION FOR ENERGY SAVING AND EMISSION REDUCTION}

The standard of energy saving and emission reduction performance auditing standard system is the unified regulations on energy saving and emission reduction issues related to performing repetitive things and activities in the process. With the scientific, comprehensive technology and practical experience based on consensus by the concerned parties and approved by competent authorities, which are released in a particular form, it become a criterion and a standard. As it is difficult to reflect a complex act or thing, it needs to establish a complete, comprehensive, dynamic standard system, from different angles, different nature path to reflect a thing. The standard system is not a certain number of standard simple list and add. The appropriate standard need cohesion, interaction, supplement the index, which will form an effective measure of the evaluation system.

The index, which as a specific information transfer intermediary and describing some numerical characteristics of things, is the quantitative description of things, and the most important is that it can reflect the key factors of a thing or feature. The establishment of energy saving performance standard system should select the energy-saving emission reduction related property standards, establish the relationship between the standard. A complete standard system is suitable and applicable, which can well measure and evaluate the performance of the implementation of energy-saving emission reduction, also provide better support and promote energy conservation and promote the implementation:

\section{A. Basic standards of performance auditing for energy saving and emission reduction}

The basic standards of performance auditing for energy saving and emission reduction is the implementation of energysaving emission reduction for the relevant environmental laws and regulations issued by the state. The state laws, regulations, 
policies, guidelines and standards for energy saving and emission reduction is the most important content in the performance audit, which measure and evaluate whether the audit subject in accordance with the overall requirements of the macro state, and whether it is conducive to sustainable development of enterprises and nation of economic benefit and environmental benefit. Only abided by the state laws, regulations and policies, the achievement of the purpose under the condition of economic benefits and environmental benefits can be recognized. The regional regulation is based on the national laws and regulations, and it is different according to the actual situation of their own development. Regional regulations is the implementation of energy-saving emission reduction standards, there are contrary to the laws of the state, based on the energy conservation and emission reduction policy.

\section{B. Performance auditing standards of specific fund for energy saving and emission reduction}

The performance audit of special funds for energy conservation not only includes the rationality of authenticity, the use of funds, audit legal compliance, but also on the capital input and output results whether reached the expected performance audit or not. The audit will be made by the index and plan, audit subject index, budget comparison, analyzing the causes related differences, summing up the feasible path to improve the economic benefits and environmental benefits, which is one of the main objectives and responsibilities of energy-saving emission reduction performance audit. The plan, budget quota index, can be the national level, regional, and audited units to develop their own plans. The index, budget, quota is often close to the actual situation of audit subjects, also has great comparability, so according to these criteria the audit results can be used to state more intuitive, not only finance performance audit of special fund for energy-saving emission reduction, but also other kinds of energy saving and emission reduction projects related to fund performance audit. This often leads to confusion because equations do not balance dimensionally. If you must use mixed units, clearly state the units for each quantity that you use in an equation.

\section{Performance auditing standards for environmental impact by Project energy consumption and emissions}

The project includes environmental projects and environmental projects. It is undeniable that there are two environmental impacts, which will produce economic benefits and environmental benefits. Anything that can be used as indicators of the data are obtained through the determination of scientific and reasonable plan, and the performance audit index data for the emerging industry is no exception. As to new technology, new technology, new products, etc., it is very difficult to obtain the relevant historical data of energy saving and emission reduction of performance audit, relevant data of the same industry or domestic and foreign counterparts, so scientific and reasonable calculation and determination is very important.

The scientific and reasonable determination of data should pay attention to the flexible application, according to the actual situation of audit subject, application and adjustment of the relevant indicators, measurement and evaluation, avoiding onesided emphasis on rigid index and ignoring the actual situation of performance audit. According to the project plan, the progress of the audit project and the completion of the project are put into use, whether to achieve the desired project. In general, there will be part of the building, part of the production, or decentralized construction completion, performance audit of energy saving and emission reduction projects requires the overall understanding and part of the energy saving and emission reduction. Of course, the performance audit is the focus of implementation in the project objective, by accurately defining the completion of the project, the project to achieve the goals, reliable and credible audit results. The main characteristics of the project's energy consumption and environmental impact of the environmental impact of the performance audit index is the effect of indicators.

\section{Performance auditing standards for management system of energy saving and emission reduction}

The energy saving management system is often used as part of the environmental management system in energy saving and emission reduction, monitoring and evaluating the continuous performance audit on this management system. At present, some enterprises have implemented the ISO ISO14001 series standard, energy saving and emission reduction in the performance audit process should contain 7 parts as.ISO14001 100 standard index, combined with the use of funds of environmental evaluation.ISO14001 includes the EMS environmental management system, environmental audit, environmental labeling, environmental performance rating, life cycle assessment, product standards in environmental standards, terms and definitions.

\section{PERFormance Auditing Standards System} CONSTRUCTION OF ENERGY SAVING AND EMISSION REDUCTION

\section{A. Frame of performance auditing standards system for energy saving and emission reduction}

Establishing the performance auditing standard system of energy saving and emission reduction is the most important relationship between the selection criteria and standards. In the continuous development of human society development, the demand of human for natural resources is increasing and development and utilization of the needs of the environment is also constantly expanding, what's more, the development of the human and the environment and using ability is also enhanced. In this process, the standard of energy saving and emission reduction performance audit can be divided into three class. The three types of standards are produced in the three aspects of human being's excessive exploitation of environment, environmental degradation and human being's active response to these aspects. There are the role model, the reaction model and the corresponding standard.

Under the background that mentioned there-in-before, it can choose the research on the evaluation index of energy conservation and emissions reduction environmental performance audit for the industrial enterprise. Based on the study of energy conservation and emissions reduction 
environmental performance audit and its evaluation index, the relevant theories of circular economy and its evaluation index system, taking how to evaluate energy conservation and emissions reduction environmental performance more effectively as my starting point.

The performance standard is the beginning of the performance auditing standard system for energy saving and emission reduction, while the role and reaction criterion is evaluating the effect and the implementation of response standards. The interaction between the three forms a cyclic structure, and changes in the standard of action leading to changes in the reaction standard and the response standard. In order to link the effect of standards and response standards for the response measures of the effect, it is based on the degree of improvement of the negative effects and the degree of positive role in the implementation of the measure. Then there is the use of matching, which is used to contact the response standards and reactionary standards, which all the response standards will eventually be assigned to the specific state of the natural environment. This standard system emphasizes integrity, which does not mean that its own will not be missing, such as policy changes, technological progress, and other uncontrollable factors. Different regions and circumstances of the audit operation will affect the system.

\section{B. Performance Auditing Standards System Construction of energy saving and emission reduction}

According to the principle of energy saving and emission reduction performance criteria, system construction principles and construction methods, the performance audit system of energy saving and emission reduction is proposed. Energy saving and emission reduction performance auditing system is hierarchical and multi-objective. Then, starting from the state, connotation and characteristics, a scientific analysis is carried out on one of the objects of the performance audit of energy saving and emission reduction. The social environment, the natural environment, and these elements are described by the reaction criterion. Finally, using more detailed and intuitive response to the standard, the reaction of the main body of the audit of energy-saving emission reduction understanding of energy-saving emission reduction performance audits to assess the behavior of the adjustment, energy-saving emission reduction performance audit system standards so as to improve the environment and make efforts.

\section{ACKNOWLEDGMENT}

The evaluation index that set up is mainly divided into two aspects, environmental impact evaluation index and economic impact evaluation index. Under the basis that setting up the evaluation index of energy conservation and emissions reduction environmental performance audit for the industrial enterprises under the perspective of circular economy, choosing three evaluation methods as the methods that can evaluate the evaluation index that setting up in this paper. They can help me realize the evaluation of energy conservation and emissions reduction environmental performance effectively. Finally, combined with a chemical industry enterprise, it finish the case analysis. In this case analysis, It analyze the rationality and feasibility of the evaluation index of energy conservation and emissions reduction environmental performance audit for the industrial enterprise under the perspective of circular economy in detail. Using the three methods that choosing to carry on the comprehensive evaluation of energy saving and emission reduction environmental performance of the chemical industry.

\section{REFERENCES}

[1] Jeronimo Burgos Jimenez,Jose Cespedes Lorente . Environmental performance as an operations objective[ J]. International Journal of Operations \& Production Management. 2011. 21(12) : 1553-1573.

[2] Gerald A Feltham,Jim Xie. Performance measure congruity and diversity inmultitask principal/agent relations $[\mathrm{J}]$. The Accounting Review. 2014. 69(3) : 429-453.

[3] Marcus Peacock. Developing environmental performance measures[J]. Industrial Engineering. 2013. 25(9) : 20-22.

[4] Ralph LKeeney. Creativity in decision making with valued-focused thinking [J].Sloan Management Review. 2010. 35(4) : 33-41.

[5] CICA.Reporting on Environmental Performance [R].Toronto. 1994.

[6] International Standard Organization . Environmental Performance Evaluation[Z].ISO/DIS14031. 2010.

[7] WBCSD. Measuring Eco-Efficiency-A Guide to Reporting Company Performance[M]. Geneva. 2000.

[8] 2008 Environmental Performance Index . Yale Center for Environmental Law\&Policy and Center for International Earth Science Information Network,http://epi.yale.edu.

[9] Carlos Domingo,Ricard Gavalda,Osamu Watanabe. Adaptive Sampling Methods for Scaling Up Knowledge Discovery Algorithms [J].Data Mining and Knowledge Discovery. 2002

[10] G.John , P.Langley. . Static Versus Dynamic Sampling for Data Mining[J].KDD-96. AAAI/MIT Press. 2006.

[11] Yanrong Li,Raj P.Gopalan. Effective Sampling for Mining Association Rules[J].AI-2004,LNAI 3339. 2004.

[12] Y. Yorozu, M. Hirano, K. Oka, and Y. Tagawa, "Electron spectroscopy studies on magneto-optical media and plastic substrate interface," IEEE Transl. J. Magn. Japan, vol. 2, pp. 740-741, August 1987 [Digests 9th Annual Conf. Magnetics Japan, p. 301, 1982.

[13] M. Young, The Technical Writer's Handbook. Mill Valley, CA: University Science, 2009. 